\title{
VEIDRODŽIO TERAPIJOS REIKŠMĖ MOTORINEI BEI SENSORINEI FUNKCIJAI, SKAUSMINIAM SINDROMUI BEI ASOCIJUOTOS GALVOS SMEGENŲ ŽIEVĖS REORGANIZACIJAI PO PERSIRGTO INSULTO
}

\author{
Monika Žilionytè ${ }^{1}$, Jurgita Savickaitè ${ }^{1}$, Andrius Kederys ${ }^{1}$, Lina Varžaitytè ${ }^{2}$ \\ ${ }^{1}$ Lietuvos sveikatos mokslu universiteto Medicinos akademija, \\ ${ }^{2}$ Lietuvos sveikatos mokslu universiteto Medicinos akademijos Reabilitacijos klinika
}

Raktažodžiai: veidrodžio terapija, insultas, skausminis sindromas, galūnių paralyžius, sensorinè funkcija, motoriné funkcija.

\begin{abstract}
Santrauka
Tyrimo tikslas - apžvelgti patikimais irodymais pagrịstą literatūrą apie veidrodinès terapijos (VT) efektyvumą pacientams, persirgusiems galvos smegenų insultu.

Tyrimo medžiaga ir metodai. Atliekant sisteminę apžvalgą, mokslinių straipsnių paieška vykdyta duomenų bazèse: PubMed, BioMedCentral, Tylor\&Francis, CohraneLibrary, ScienceDirect. Mokslinių straipsnių paieška atlikta pagal kiekvienai duomenų bazei pritaikytą specialią paieškos strategiją. Paieškai buvo panaudoti šie raktažodžiai: ,,mirror therapy“, ,,rehabilitation“, ,, stroke ", ,, upper limb ", ,, recovery of function ", ,, mirror movement", „, phantom limb pain ,,, ,mirror visual feedback", ,,mirror neurons system ". I I sisteminę apžvalgą įtraukti anglų kalba 2008-2016 metais publikuoti atsitiktinių imčiu kontroliuojami arba kontroliuojami prieš ir po tyrimai, kuriuose buvo vertinama VT įtaka paralyžiuotos galūnès motorinei ir sensorinei funkcijai, skausmo intensyvumui bei asocijuotos galvos smegenų žievès reorganizacijai. Tyrimo rezultatai. I sisteminę apžvalgą ịtraukta 11 tyrimų. Tyrimuose buvo suformuotos dvi grupès: tiriamųjų, kuriems buvo taikyta standartinè bei VT, ir kontrolinè grupé, kuriai buvo taikoma tik standartinè terapija. Daugelyje tyrimų VT taikyta vieną mènesį. Rezultatai buvo vertinami prieš taikytą terapiją ir po jos. Apžvelgus visus šiuos 11 straipsnių stebime, kad tose tiriamuju grupèse, kuriose naudojama
\end{abstract}

VT, ženkliai pagerèja pacientų paralyžiuotos galūnès motorinè funkcija, padideja vikrumas, sumažeja skausmas.

Išvados. VT didina smegenų aktyvumą ipsilateralinèje motorinèje žievèje, somatosensorinèje zonoje, skatina asocijuotos žievès reorganizaciją, taip pat ji padeda pasiekti geresnių rezultatų pacientams, patyrusiems nedominuojančio pusrutulio insultą, sumažina persirgus insultu atsiradusị skausmą bei padidina po insulto sumažèjusi galūnių vikrumą. VT yra veiksminga ne tik gydant ūmiu ir poūmiu insultu, tačiau ir lètiniu galvos smegenų insultu sergančius pacientus.

\section{Ivadas}

Insultas - ūmus židininis galvos smegenų kraujotakos sutrikimas. Sergamumas ir mirtingumas dèl galvos smegenų insulto pasaulyje užima trečiają vietą. Norint išvengti komplikacijų, insultą patyrusiems pacientams būtina kuo anksčiau pradèti taikyti reabilitacijos priemones. Veidrodžio terapija (VT) yra vienas iš reabilitacijos metodų, skirtų pacientams, persirgusiems insultu. Šis metodas paprastas ir pigus, tačiau nepaisant privalumų veikimo mechanizmas išlieka ne visai aiškus [1]. Žinomi du VT veikimo mechanizmai: pirminès motorinès žievès (MŽ) ir veidrodinių neuronų (VN) sistemos aktyvinimas [2]. Judinant neą galūnę, veidrodyje sukuriamas priešingas atspindys, kuris sukuria neparalyžiuotos galūnès vizualinę iliuziją, stiprinančią os galūnès gebejjimą judèti [3]. Šis procesas suaktyvina propriocepciją ir MŽ smegenų dali, kuri apima paralyžiuotos galūnès normalų judejjimą [4]. Literatūroje kol kas nèra daug duomenų apie tai, kaip VT veikia asocijuotą galvos smegenų žievę bei motorinę ir sensorinę paralyžiuotos galūnès funkcijas, o duomenys apie šios terapijos efektyvumą 
gydant skausmini sindromą (SS) po persirgto galvos smegenų insulto iki šiol išlieka kontraversiški. Reikia daugiau tyrimų, kuriais remiantis būtų galima ịvertinti VT efektyvumą gydant liekamuosius reiškinius pacientams, patyrusiems galvos smegenų insultą.

Tyrimo tikslas - apžvelgti patikimais įrodymais pagrịstą literatūrą apie VT efektyvumą pacientams, persirgusiems galvos smegenų insultu.

\section{Metodika}

Mokslinès publikacijos buvo ieškomos naudojantis duomenų bazemis: PubMed, BioMedCentral, Tylor\&Francis, CohraneLibrary, ScienceDirect. Mokslinių straipsnių paieška atlikta pagal kiekvienai duomenų bazei pritaikytą specialią paieškos strategiją. Paieškai buvo panaudoti šie raktažodžiai: ,,mirrortherapy“, "rehabilitation“, „,stroke“, „, upper limb “, ,, recovery of function “, ,, mirror movement “, „,phantom limb pain ", ,, mirror visual feedback", ,, mirror neurons system". Elektroniniams duomenims kaupti bei rūšiuoti buvo naudojama RefWorks sistema. Ne visi pagal raktažodžius rasti literatūros šaltiniai buvo ịtraukti ị sisteminę apžvalgą. Mokslinių publikacijų atranka buvo vykdoma remiantis tam tikrais kriterijais. İ sisteminę apžvalgą nebuvo įtraukti straipsniai: 1) parašyti ne anglų kalba, 2) visas straipsnio tekstas nebuvo prieinamas arba straipsnis buvo mokamas, 3) straipsniai, kuriuose aprašomas pilotinis tyrimas, 4) straipsniai, kuriuose VT nebuvo pagrindinis terapijos būdas, 5) pasikartojantys straipsniai. Atmetus šiuos kriterijus atitinkančius straipsnius buvo rasti moksliniai straipsniai, publikuoti 2008 - $2016 \mathrm{~m}$. I sisteminę apžvalgą ịtrauktų tyrimų metodologinis tikslumas ir kokybe įvertinti naudojant NICE (National Institute for Health and Care Excellence) tyrimų kokybès vertinimo įrankị [25]. Kiekvieno tyrimo kokybė buvo ịvertinta tam tikru kokybès lygiu: ++ (aukšta) - atitinka visus arba daugumą tyrimų kokybès kriterijų ir tikètina, kad tokio tyrimo rezultatai arba išvados negali būti kitokie nei pateikti; + (priimtina) - atitinka kai kuriuos tyrimu kokybės kriterijus ir mažai tikètina, kad tokio tyrimo rezultatai arba išvados gali būti kitokie nei pateikti; - (žema) - neatitinka nè vieno arba atitinka tik kelis tyrimų kokybès kriterijus ir įmanoma, kad tokio tyrimo rezultatai arba išvados gali būti kitokie nei pateikti ir gali keistis. Toliau pateikiama šių mokslinių publikacijų analizè.

\section{Rezultatai ir ju aptarimas}

Buvo apžvelgta 11 mokslinių tyrimų, kuriuose buvo vertinama VT ịtaka pažeistos galūnès motorinei, sensorinei funkcijai, skausmo intensyvumui bei asocijuotos galvos smegenų žievès reorganizacijai. Daugelyje tyrimų buvo suformuotos dvi grupės: tiriamųų, kuriems buvo taikyta standartinè bei VT, ir kontrolinè grupè, kuriai buvo taikoma tik standartinè terapija (ST). Daugelyje tyrimų VT taikyta vieną ménesį. Rezultatai buvo vertinami prieš taikytą terapiją ir po jos.

VT reikšmè motorinei funkcijai. Sumažejjusi motorinè funkcija ir pakitusi jos kontrolè kartu su padidejusiu raumenų tonusu yra vieni iš dažniausių klinikinių iššūkių gydant insultą patyrusius pacientus. Nuo 55 proc. iki 75 proc. pacientų, persirgusių galvos smegenų insultu, turi paralyžiuotą vieną ar kelias galūnes [12]. VT veikimo mechanizme didelè reikšmè teikiama veidrodiniams neuronams (VN). Tai yra nervinès ląstelès, turinčios vizualines-motorines ypatybes. Jos išsidèsčiusios F5 smegenų zonoje, kurią turi beždžionès [20]. Šio tipo nervinių ląstelių yra ir žmogaus smegenyse, jos aktyvuojamos tada, kai atliekamas judesys yra stebimas. Pirmą kartą VT literatūroje aprašè 1990 m. Altshulter su bendraautoriais. Ši terapija taikyta kaip reabilitacijos metodas pacientams su vienos pusès paralyžiumi. Autorių nuomone, VT pagerina paralyžiuotų galūnių judesių atlikimą [21].

2016 m. Tongji reabilitacijos ligoninejje Kinijoje tirta 10 pacientų: 5 persirgę smegenų insultu, atitinkantys šiuos kriterijus: 1) vienos pusès smegenų insultas su kairès pusès galūnių paralyžiumi, 2) po insulto praejjęs vienas mėnuo, 3) padidèjęs raumenų tonusas, 4) išlikęs supratimas vykdyti žodinius nurodymus. Kontrolinę grupę sudare 5 sveiki asmenys. Pacientai, naudojant specialius akinius, stebèjo savo čiurnos judesius netaikant ir taikant VT. Visiems 10 tyrime dalyvavusių asmenų buvo atliekamas funkcinis magnetinio rezonanso tyrimas, kurio metu stebèta, kurios smegenų sritys aktyvuojamos. Sergantiesiems taikant VT susidariusi kairès čiurnos judesių iliuzija sukèlè stiprų aktyvumą ipsilateralinèje sensomotorinèje žievejje, pakaušiniame vingyje, priekiniame prefrontaliniame vingyje. Kontrolinès grupès tiriamiesiems VT sukèlè abipusį MŽ aktyvumą $(\mathrm{p}<0,005)$. Netaikant VT buvo stebètas aktyvumas įvairiose smegenų srityse (priešcentriniame, užcentriniame, smilkininiame vingiuose, smegenèlių užpakalinèje skiltyje) [1]. Apibendrinant ši tyrimą, galima teigti, jog judinant neparalyžiuotą galūnę veidrodyje sukuriamas priešingas atspindys, kuris padeda sukurti vizualinę iliuziją didinant paralyžiuotos galūnès gebejjimą judèti. Suaktyvinama MŽ smegenų dalis, kuri užtikrina paralyžiuotos galūnès normalų judèjimą.

Asmenims, patyrusiems insultą nedominuojančiame smegenų pusrutulyje, VT buvo veiksmingesnè nei tiems, kurie persirgo dominuojančio pusrutulio insultu. Tai įrode Lenkijos reabilitacijos centre atliktas tyrimas, kuriame dalyvavo 60 tiriamujų dešiniarankių ( 24 moterys ir 36 vy- 
rai). Itraukimo kriterijai: $>2$ mėn. po insulto; nesutrikusios pažintinès funkcijos, nesunkus rankos motorinès funkcijos sutrikimas. Tiriamieji atsitiktinai suskirstyti ị dvi grupes: 1 grupę sudare 30 asmenų, kuriems taikyta VT paralyžiuotajai rankai, 2 grupę sudare 30 asmenų, sudarančių kontrolinę grupę. Pirmajai grupei VT taikyta 21 dieną, 5 kartus per savaitę, 2 kartus per dieną po 15 minučių pagal sudarytą programą. Prieš VT taikymą ir praejjus 21 dienai po užsièmimų pacientų funkcijos vertintos naudojant specialius testus. Lyginant tiriamuju grupes, nustatytas ženkliai geresnis terapinis atsakas toje tiriamujų grupeje, kurioje taikyta VT, ir ypač vyresniems pacientams, turejjusiems nedominuojančio pusrutulio insultą [5].

Iš trijų reabilitacijų centrų Olandijoje (Rijndam, Blixembosch, Leijpark) klinikiniam tyrimui buvo atrinkti 103 pacientai, kurie buvo persirgę insultu prieš 6 mènesius, paralyžiuotos viršutinès galūnès funkcijos pagal Brunnstrom skalę III - VI [8]. Šie pacientai atsitiktinai suskirstyti i 5 grupes. Pirmos grupès pacientai užduotis atliko silpnesniaja ranka ir ją stebejjo, antros grupès tiriamieji atliko užduotis sveikaja ranka, stebėdami ją veidrodyje, trečios grupès - užduotis atliko sveikaja ranka, veidrodyje ją stebėdami, ketvirtos grupès - užduotis atliko abiem rankomis, esant ekranui tarp jų, nematydami silpnesnès rankos, penktos grupes pacientai užduotis atliko taip pat kaip ir ketvirtos grupès tiriamieji, tačiau veidrodyje stebejjo sveikają ranką, bandydami įsivaizduoti, kad veiksmus atlieka silpnesniąja ranka. Tiriamieji turejo suimti kamuoliuką, rodomuoju pirštu nuvesti nuo taško A iki taško B. Judesio greitis vertintas kiekvieno užsièmimo metu. Norint išmatuoti judesių atlikimo greitị buvo naudojama 3 dimensijų sistema, ant rodomojo piršto pritvirtinant jutiklị. Labiausiai teigiami rezultatai stebėti pirmoje grupèje. Mažiausias efektyvumas buvo 2 ir 5 grupèse. Lyginant 2 ir 3 grupes, ženklus judesio greičio padidejjimas buvo stebetas 3 grupeje, kurioje buvo taikyta VT $(\mathrm{p}=0,078)[10]$.

Olandijos Roterdamo reabilitacijos centre 2015 m. atliktas tyrimas, jame dalyvavo 37 pacientai, kurie buvo bent 6 mènesius po insulto, o paralyžiuotos viršutinès galūnès funkcija pagal Brunnstrom skalę III - VI. Tiriamieji atsitiktinai suskirstyti i dvi grupes: 1 - aktyvaus stebejjimo, 2 - kontrolinè. Tiriamieji atliko 10 judesių sveikaja viršutine galūne, kurie buvo nufilmuoti ir įrašyti. Taip pat buvo atlikta 10 judesių paralyžiuota ranka. Tiriamieji pirštais turejjo nuvesti atstumą nuo taško A iki taško $B$. Norint išmatuoti judesių greitị buvo naudota 2 dimensijų sistema ant riešo pritvirtinant daviklį. Antroje tyrimo dalyje ekrane 1 grupès tiriamiesiems buvo rodoma pirmame tyrimo etape nufilmuota medžiaga, o 2 grupès tiriamiesiems buvo rodomi statiniai kraštovaizdžio vaizdai. Pacientai žiūrèjo vaizdo medžiagą 3 minutes, po to atliko 30 pirmame tyrimo etape nurodytų judesių. Tuomet du kartus iš eilès po 1 minutę vél stebejo vaizdus ekrane ir atitinkamai po 20 kartų atliko tuos pačius judesius. Minutę pažiūrejus ị ekrane esantị vaizdą ir po to patraukus monitorių, pacientas turejo atlikti viso tyrimo metu kartotus judesius silpnaja ranka. Judesiai ženkliai pagreitejo abiejose grupėse: 18,3 proc. 1 grupeje ir 9,1 proc. 2 grupejje. Lyginant abi grupes, judesiu atlikimo laikas ženkliai sutrumpejo pirmoje grupejje $(p=0,026)[10]$.

Taikant VT ne tik sumažeja rankos skausmas ir pagerèja motoriné funkcija, bet ir padidejja vikrumas. Tai atskleidè Sarah Tyson su bendraautoriais $2015 \mathrm{~m}$. atliktame tyrime. Dvylikoje Šiaurès Vakarų Anglijos reabilitacijos ligoninių buvo pakviesti dalyvauti tyrime 944 pacientai, iš jų atrinkti 94, atitinkantys šiuos kriterijus: 1) 1 savaite ir ilgiau praejusi po insulto bei pasireiškęs galūnių silpnumas, 2) nèra kitų ligų, sunkinančių viršutinių ir apatinių galūnių motorines funkcijas, 3) nesutrikusios pažintinès funkcijos. Atsitiktiniu būdu tiriamieji suskirstyti į dvi grupes: pirmą grupę sudarè 63 pacientai, kuriems taikyta VT, antrą grupę - 31 pacientas, kuriems taikyta kineziterapija. Po 4 savaičių įvertinus abi grupes pagal Box and Block testą ir motorikos indeksą (MI) galūnès raumenų jèga $(\mathrm{SD}=9,1)$ ir vikrumas $(\mathrm{SD}=8,2)$ buvo didesni pirmoje grupeje, lyginant su kontroline grupe ( $\mathrm{SD}=6,8, \mathrm{p}=0,57 ; \mathrm{SD}=6,0, \mathrm{p}=0,42$ ). Po 8 savaičių galūnès raumenu jèga $(\mathrm{SD}=12,9)$ ir vikrumas $(\mathrm{SD}=9,3)$ buvo didesni pirmoje grupeje, lyginant su kontroline grupe $(\mathrm{SD}=10,5$, $\mathrm{p}=0,63 ; \mathrm{SD}=7,0, \mathrm{p}=0,93)[11,12]$.

M. Inverzinni su bendraautoriais 2013 metais atliko prospektyvinį randomizuotą tyrimą, kurio tikslas buvo nustatyti, ar kartu su ST taikoma VT padeda pagerinti motorinę viršutinès galūnès funkciją pacientams po poūmio galvos smegenų insulto. Tyrime dalyvavo 26 pacientai, galvos smegenų insultą patyrę prieš mažiau nei 4 savaites, turintys viršutinès galūnès paralyžių. Pacientai atsitiktinai suskirstyti ị dvi grupes: pirmą grupę sudare 13 pacientų, kuriems taikyta tik ST, antrają grupę sudare 13 pacientų, kuriems kartu su ST taikyta 30 minučių trukmès VT. Po menesio taikytos terapijos abiejų grupių pacientams atlikti specialūs testai: rankos judesių tyrinejjimo testas (ARAT), motorikos indeksas (MI), funkcinio nepriklausomumo testas (FIM). Lyginant atliktų testų rezultatus nustatyta, jog viršutinès galūnès motorinè funkcija pagerèjo abiejų grupių pacientams, tačiau testų rezultatai buvo geresni antroje grupejje [13].

Apatinès galūnès motorinès funkcijos sutrikimas sukelia tam tikrus eisenos pakitimus. Sang Guli su bendraautoriais $2015 \mathrm{~m}$. atliko randomizuotą tyrimą, kurio tikslas buvo ịvertinti VT ịtaką eisenos gerejjimui pacientams, patyrusiems poūmị galvos smegenų insultą. Tyrime daly- 
vavo 34 pacientai, kurie buvo atsitiktinai suskirstyti ị dvi grupes: tiriamoji grupé, kuriems taikyta VT, ir kontroliné grupè, kuriems taikyta ST. Tiriamosios grupès pacientams 5 dienas per savaitę, vieną mènesị taikyta apatinių galūniu VT. Prieš ir po terapijos buvo vertinamos eisenos charakteristikos: stovèsena, žingsnio ilgis, žingsnio plotis, pèdos pakrypimas, ejjimo greitis bei ritmas. Tiriamoje grupejje statistiškai reikšmingai pagerèjo stovèsena bei žingsnio ilgis. Kitos eisenos charakteristikos taip pat buvo geresnès tiriamųjų grupejje [14].

VT reikšmė skausmui. VT veiksminga ne tik atstatyti po insulto susilpnèjusią motorinę funkciją, tačiau ir malšinti atsiradusį skausmą. Tai nustatyta remiantis La Sapienza universitete Romoje 2009 m. atliktu tyrimu, kuriame dalyvavo 24 pacientai, prieš 14 mènesių sirgę insultu (11 vyrų ir 13 moterų). Tiriamujų amžiaus vidurkis buvo $62 \mathrm{~m}$. Paralyžiuotoje rankoje lètinis regioninio SS diagnozuotas remiantis Bruehl kriterijais [6]. I tyrimą neitraukti pacientai, kuriems buvo pažeistas gumburas, peties rezginys, sergantys depresija. Visi 24 pacientai buvo atsitiktinai suskirstyti i 3 grupes: pirma grupe - taikyta ST; antra grupé - netaikyta VT; trečia grupe - taikyta ịsivaizdavimo terapija, kurios metu pacientai turèjo ịsivaizduoti, kad judina paralyžiuotą ranką. Pirmos ir antros grupés pacientai atliko distalinius ir proksimalinius rankos judesius 30 minučių per dieną 4 savaites. Tyrimo pradžioje ir po 4 savaičių pacientų skausmo intensyvumas buvo vertinamas pagal vizualinių analogų skalę (VAS) [7]. Pirmoje grupèje skausmas pagal VAS sumažèjo 88 proc. pacientų, antroje grupeje skausmas sumažejo 12 proc. pacientu, 25 proc. - skausmas nepakito, 62 proc. - skausmas padidejjo. Trečioje grupejje 25 proc. pacientų skausmas sumažèjo, o 75 proc. - padidèjo. Pacientai, kuriems skausmas padidejo, nebuvo ịtraukti $i$ antrą tyrimo etapą. Likę $(\mathrm{n}=12)$ pacientai tęsè tyrimą, gaudami VT 4 savaites. Po šio etapo 92 proc. pacientų skausmas sumažejo. Pradejjus taikyti veidrodžio terapiją 2 ir 3 grupèms taip pat stebètas ženklus skausmo sumažejimas $(\mathrm{p}=0,002$, $\mathrm{p}=0,004)$.

VT reikšmė galvos smegenų žievės reorganizacijai. Intensyvus treniravimasis padeda pagerinti ne tik motorinę pažeistos galūnès funkciją, bet ir skatina asocijuotos žievès reorganizaciją. Dar nèra tiksliai nustatyta, kaip VT veikia žievės reorganizaciją, tačiau yra manoma, kad terapijos metu stebint veidrodyje atsikartojančius sveikos galūnès judesius sukeliamas papildomas neuronų aktyvumas pažeisto pusrutulio atitinkamose motorinèse zonose, kuris gali lemti žievès reorganizavimąsi bei funkcijos pagerejjimą [16]. Manoma, kad veidrodinė iliuzija sukuria geresnę treniravimosi aplinką, dèl somatosensorikos dideja aktyvumas MŽ arba aktyvumą gali sukelti padidèjęs dèmesio su- telkimas į reikiamą atlikti užduotį. Marian A. Michielsen su bendraautoriais $2011 \mathrm{~m}$. atliktame randomizuotame kontroliuojamame tyrime vertino VT klinikini efektą bei vèlyvają smegenų žievès reorganizaciją tarp pacientų, sergančių lètiniu galvos smegenų insultu bei turinčiu viršutinių galūnių parezę. Tyrime dalyvavo 40 pacientų, kurie galvos smegenų insultą buvo patyrę prieš 3,9 metus. Motorinès funkcijos vertinimui naudotas Fugl-Meyer (FM) testas. Buvo vertinama rankų jèga, raumenu tonusas, skausmas, vikrumas. Aktyvumo kitimas tam tikrose galvos smegenu dalyse vertintas atliekant funkcinį MR. Vertinant rezultatus buvo nustatyta, kad FM testo rezultatai buvo geresni pacientams, kuriems taikyta VT, tačiau pagerejjimas nebuvo ilgalaikis. Funkcinis MR parodé, kad aktyvumo perejimas nuo pirminès MŽ link pažeisto galvos smegenų pusrutulio buvo stebimas tik pacientams, kuriems taikyta VT [15]. Šis tyrimas atskleide, kad VT yra veiksminga ne tik gydant ūmiu bei poūmiu insultu sergančius pacientus, tačiau ir sergančius lètiniu galvos smegenų insultu [17].

VT reikšmė pažeistos galūnès sensorinei funkcijai. VT terapija turi poveiki ne tik motorinei, bet ir sensorinei funkcijai. Sensorinès funkcijos pagerèjimas patvirtina, kad yra ryšys tarp regejjimo ir jutimo. Buvo įrodyta, kad judesių stebejjimas moduliuoja ne tik MŽ aktyvumą, bet ir žievès somatosensorinès zonos aktyvumą. Matant judančią kūno dalị gerèja gebejjimas atskirti judančią ir nejudančią galūnes, pakinta aktyvumas pirminèje sensorinejje žievejje [18] Christian Dohle su bendraautoriais 2009 m. atliko tyrimą, kuriame dalyvavo 36 pacientai su hemipareze, kuriems insultas buvo įvykęs prieš 8 savaites. Buvo suformuotos tiriamoji bei kontroliné grupès. Pacientai buvo testuojami naudojant FM testą, neuropsichologinius testus. Motoriné funkcija bei paviršinis jautrumas ženkliai pagerejjo tiriamujų grupeje, kuriems taikyta VT [19]. Taigi VT turi gerą poveikị ne tik gydant vienos galūnès pažeidimą, tačiau ir hemiparezės atveju. Žiūrint kaip juda sveika ranka, buvo nustatyta stipresne pažeisto pusrutulio stimuliacija nei stebint paralyžiuotos pusès galūnių judesius. Tai reiškia, kad VT turi didesni poveikị nei ịprastinè paralyžiuotų galūnių kineziterapija.

Ching-YiWu su bendraautoriais $2013 \mathrm{~m}$. atliko darbą, kuriame buvo tiriama, kaip VT padeda atstatyti sensorinę funkciją pacientams, sergantiems lètiniu insultu. Tyrime dalyvavo 33 pacientai su nežymiu bei vidutiniu galūnès motorinès funkcijos pablogėjimu. Tiriamųų grupę sudarè 16 pacientu. VT buvo taikoma 1,5 val. per dieną, 5 dienas per savaitę, vieną mènesį. Sensorinei funkcijai vertinti buvo naudotas Revised Nottingham Sensory Assessment testas [21].

Temperatūros jutimas ženkliai pagerèjo tiriamuju gru- 
pejje lyginant su kontroline. Tai gali būti susiję su multimodaliniais neuronais, kurie išsidèstę užpakalinèje parietalinèje ir premotorinèje žievès dalyse [22]. Jie atsako ị sensorinį dirgiklį kaip ị vizualinę informaciją taip pat gerai, kaip i judesio dirgikli [23]. Vizualinè iliuzija VT metu gali suteikti sensorinę informaciją, kuri gali moduliuoti somatosensorinès žievès tinklą ir taip prisidèti prie jutimo pagerèjimo [24]. Temperatūros bei skausmo jutimo pagerèjimas pacientams po insulto paprastai atsistato greičiau nei propriocepcija bei paviršiniai jutimai [22].

Taigi apžvelgus visus šiuos 11 straipsnių stebime pasikartojančią tendenciją tose tiriamujų grupèse, kuriose naudojama VT, ženkliai pagerèja pacientų paralyžiuotos galūnès motorinè funkcija, padidèja vikrumas, sumažèja skausmas. Nepaisant to, kad atrenkant į tyrimus tinkamus pacientus taikomi griežti atrankos kriterijai (dažniausi: persirgtas insultas, nèra kitų gretutinių ligų, lemiančių sutrikusią galūnių funkciją), tinkamų asmenų skaičius yra labai didelis. Atsižvelgiant $\mathfrak{i}$ tai galime teigti, jog insultas ir jo liekamieji reiškiniai (SS ir visiška arba dalinè galūnių parezė) išlieka aktuali problema, kurią gali išspręsti tik tinkamai parinkta gydymo taktika ir efektyvios reabilitacijos priemonès.

\section{Išvados}

1. VT skatina asocijuotos žievès reorganizaciją, didina smegenų aktyvumą ipsilateralinèje motorinèje žievèje, somatosensorinejje zonoje, taip gerindama paralyžiuotos galūnès motorinę funkciją.

2. Taikant šią terapiją geresnių rezultatų pasiekia tie pacientai, kurie patyrẻ nedominuojančio pusrutulio insultą lyginant su tais, kurie patyré dominuojančio pusrutulio insultą.

3. VT veiksmingai sumažina po insulto atsiradusi skausminị sindromą bei atstato sumažèjusį galūnių vikrumą.

4. Ši terapijos rūšis padeda pagerinti sensorinę paralyžiuotos galūnès funkciją moduliuojant somatosensorinès žievès aktyvumą bei veiksminga ne tik gydant ūmiu ir poūmiu insultu, tačiau ir lètiniu galvos smegenų insultu sergančius pacientus.

\section{Literatūra}

1. Feng G, Qun X, Hassan M. et al. The neuronal correlates of mirror therapy: A functional magnetic resonance imaging study on mirror-induced visual illusions of ankle movements. Brain Research 2016; 1639:186-193.

http://dx.doi.org/10.1016/j.brainres.2016.03.002

2. Lamont K, Chin M, Kogan M. Mirror box therapy — seeing is believing. Explore: The Journal of science and healing 2011;
7: 369-372.

http://dx.doi.org/10.1016/j.explore.2011.08.002

3. Thieme H, Bayn M, Wurg M. et al. Mirror therapy for patients with severe arm paresis after stroke - a randomized controlled trial. Clinical rehabilitation 2012; 4(27):2.

4. Lee MM, Cho H, Song $\mathrm{CH}$. The mirror therapy program enhances upper-limb motor recovery and motor function in acute stroke patients. American Journal of Physical Medicine \& Rehabilitation 2012; 8(91):689-700.

http://dx.doi.org/10.1097/PHM.0b013e31824fa86d

5. Radajewska A, Opara J, Bilinski G. et al. Effectiveness of mirror therapy for subacute stroke in relation to chosen factors. Rehabilitation nursing 2016; 41(2).

http://dx.doi.org/10.1002/rnj.275

6. Norman Harden R, Bruehl S, Perez RS. et al. Validation of proposed diagnostic criteria for complex regional pain syndrome. Pain 2010; 150:268-272.

http://dx.doi.org/10.1016/j.pain.2010.04.030

7. Kersten P, Kucukdeveci AA, Tennant A. The use of the Visual Analogue Scale (VAS) in rehabilitation outcomes. J Rehabil Med 2012; 44(7):609-10.

http://dx.doi.org/10.2340/16501977-0999

8. Kollen B, Lennon S, Lyons B. et al. The effectiveness of the Bobath concept in stroke rehabilitation: what is the evidence? American Heart Association Journal 2009; 40(4):89-97.

http://dx.doi.org/10.1161/strokeaha.108.533828

9. Selles RW, Michielsen ME, Bussmann JB. et al. Effects of a mirror-induced visual illusion on a reaching task in stroke patients: implications for mirror therapy training. Neurorehabilitation and Neural Repair 2014; 28 (7): $652-659$.

http://dx.doi.org/10.1177/1545968314521005

10. Wouter J, Harmsen MS, Johannes BJ. et al. A mirror therapy -based action observation protocol to improve motor learning after stroke. Neurorehabilitation and Neural Repair 2015; 29(6): $509-516$.

http://dx.doi.org/10.1177/1545968314558598

11. Chen HM, Chen CC, Hsueh IP. et al. Test-retest reproducibility and smallest real difference of 5 hand function tests in patients with stroke. Neurorehabil Neural Repair 2009; 23(5):435-440. http://dx.doi.org/10.1177/1545968308331146

12. Tyson S, Wilkinson J, Thomas N. et al. Phase II pragmatic randomized controlled trial of patient-led therapies (mirror therapy and lower-limb exercises) during inpatient stroke rehabilitation. Neurorehabilitation and Neural Repair 2015; 29(9): 818 -826. http://dx.doi.org/10.1177/1545968314565513

13. Invernizzi $M$, Negrini $S$, Carda $S$. et al. The value of adding mirror therapy for upper limb motor recovery of subacute stroke patients: the randomized controlled trial. European Journal of Physical and Rehabilitation Medicine 2013; 49: 311-317.

14. Ji SG, Kim MK. The effects of mirror therapy on the gait of subacute stroke patients: a randomized controlled trial.Clinical 
Rehabilitation 2015; 29 (4): 348 -354.

http://dx.doi.org/10.1177/0269215514542356

15. Michielsen ME, Selles RW, van der Geest JN. et al. Motor recovery and cortical reorganization after mirror therapy in chronic stroke patients: a phase II randomized controlled trial. Neurorehabilitation and Neural Repair 2011; 25 (3):223 -233. http://dx.doi.org/10.1177/1545968310385127

16. Burzi V, Tealdi G, Boyd RN. et al. Action observation in infancy: implications for neuro-rehabilitation. Dev Med Child Neurol 2016; 58(4):74-7. http://dx.doi.org/10.1111/dmcn.13048

17. Yavuzer G, Selles R, Sezer N. et al. Mirror therapy improveshand function in subacute stroke: a randomized controlled trial. Archives of Physical Medicine and Rehabilitation 2008;89:393-398. http://dx.doi.org/10.1016/j.apmr.2007.08.162

18. Dohle C, Püllen J, Nakaten A. et al. Mirror therapy promotes recovery from severe hemiparesis: a randomized controlled trial. Neurorehabil Neural Repair 2009;23(3):209-17 http://dx.doi.org/10.1177/1545968308324786

19. Dohle C, Püllen J, Nakaten A. et al. Mirror therapy promotes recovery from severe hemiparesis: a randomized controlled trial. Neurorehabilitation and Neural Repair 2009; 23: 209-217. http://dx.doi.org/10.1177/1545968308324786

20. Ti-Fei Yuan A, Robert H. Mirror neuron system based therapy for emotional disorders. Medical Hypotheses 2008; 71: $722-726$.

http://dx.doi.org/10.1016/j.mehy.2008.07.004

21. Marian E, Michielsen, Ribbers GM. et al. The neuronal correlates of mirror therapy: an fMRI study on mirror induced visual illusions in stroke patients. Journal of Neurology, Neurosurgery and Psychiatry, BMJ Publishing Group 2010; 82: 393.

22. Holly E, Rossiter Mimi R, Borchert RJ. et al. Cortical mechanisms of mirror therapy after stroke. Neurorehabil Neural Repair 2015; 29: 444-452. http://dx.doi.org/10.1177/1545968314554622

23. Ippei N, Tatsuya M, Koganemaru S. et al. Human motor plasticity induced by mirror visual feedback. J. Neurosci 2012; 32 : 1293-1300.

http://dx.doi.org/10.1523/JNEUROSCI.5364-11.2012

24. Hamzei F, Läppchen CH, Glauche V. et al. Functional plasticity induced by mirror training: the mirror as the element connecting both hands to one hemisphere. Neurorehabil Neural Repair 2012; 26:484-496.

http://dx.doi.org/10.1177/1545968311427917
25. Methods for the development of NICE public health guidance. NICE, 2012.

\section{MIRROR THERAPY INFLUENCE ON MOTORIC AND SENSORY FUNCTIONS, ALSO PAIN SYNDROME AND ASSOCIATIVE BRAIN CORTEX REORGANIZATION AFTER STROKE \\ M. Žilionytė, J. Savickaitė, A. Kederys, L. Varžaitytė}

Key words: mirror therapy, stroke, pain syndrome, limb paralysis, sensor function, motoric function.

Summary

Aim: to overview strong evidence-based literature, related to mirror therapy (MT) efficiency on patients after head brain stroke.

Research material and methods: systemic analysis was grounded by academic articles, found in the following databases: PubMed, BioMedCentral, Tylor \&Francis, Cohrane Library, Science Direct. Search of academic articles has been performed according to the strategies, adapted to each database. The following keywords have been applied: "mirror therapy", "rehabilitation", "stroke", "upper limb", "recovery of function", "mirror movement", "phantom limb pain ", "mirror visual feedback", "mirror neurons system". Systemic summary contained random controlled or not controlled researches "before and after", published in 2008-2016 in English. The abovementioned assessed MT impact on motoric and sensory functions of paralysed limb, also pain intensity and reorganization of an associated brain cortex.

Results: systemic analysis involved 11 researches, divided into two groups: respondents, applied with a standard and MT and a control group, applied with a standard therapy only. The majority of researches were based by 1 month MT application. The results were assessed before the therapy and after it. The analysis of 11 articles has shown that the MT groups featured significant improvement of motoric function of the paralysed limb, also increased movement capacity and decreased pain.

Conclusions: MT increased brain activity at ipsilateral motoric cortex and somatosensory zone, also promotes reorganization of associated cortex thus helping to gain better results for the patients after non-dominant hemisphere stroke, decreases after-stroke pain and improves movement capacity of limbs. MT is efficient not only treating patients with acute and after acute stroke, but also those with chronic one.

Correspondence to: lina.varzaityte@gmail.com

Gauta 2016-10-18 